\title{
The Balance Sheet Strategy of the Central Bank in the Financial Economic Cycle
}

\section{Zhang Dingding}

Faculty of Economics and Law, Zhejiang University of Commerce and Industry Hangzhou Business School, Hangzhou, China

\section{Email address:}

13967040653@qq.com

\section{To cite this article:}

Zhang Dingding. The Balance Sheet Strategy of the Central Bank in the Financial Economic Cycle. Science Innovation. Vol. 6, No. 4, 2018, pp. 220-224. doi: 10.11648/j.si.20180604.18

Received: June 22, 2018; Accepted: July 12, 2018; Published: July 20, 2018

Abstract: In recent years, China's economic growth has been slowing down, asset prices have started to drop, and China's economy has entered the downward phase of the financial economic cycle. Facing this development situation, in order to make economic development continue to keep in good health condition, to make appropriate adjustments in the original economic framework, should build a multi-objective function, which can be more effectively to the target detection and control. In this paper, the balance sheet strategy of the central bank is briefly discussed based on various mechanisms of the balance sheet.

Key words: Financial and Economic Cycles, The Central Bank, Balance Sheet

\section{金融经济周期下中央银行资产负债表策略}

\section{张鼎鼎}

经法分院, 浙江工商大学杭州商学院, 杭州, 中国

\section{邮箱}

13967040653@qq.com

摘要: 近年来, 中国的经济增长持续放缓, 资产价格开始走低, 中国的经济开始进入金融经济周期的下行阶段。面对 这一发展现状, 为了让经济发展继续保持健康良好的状态, 必须对原有的经济框架做出适当的调整, 应该构建多目标 的函数, 从而能更有效地对各个目标进行检测与把控。本文以资产负债表的各项机制为出发点, 对中央银行资产负债 表策略进行简要探讨。

关键词：金融经济周期，央行，资产负债表

\section{1. 引言}

金融经济周期，在孙双鹰的《金融经济周期理论研究 动态》（2017）一文中被定义为金融体系显著影响经济周 期的运作规律, 也可以被通俗的理解为为抵抗外部冲击, 金融体系通过传到会产生的周期性变化。在如今, 金融经 济周期对市场影响日益显著的当下, 中央银行资产利率负 债表的构建框架也必将迎来新的转型, 何德旭等在《构建
金融经济周期下的中国利率走廊模式》（2017）一文中， 针对于中央银行对流通货币控制度下降、货币迷失与漏损 频繁等现象, 提出了利率走廊这一概念, 希望以此来降低 中央资产负债表的错配问题。而颜博在《中央银行资产负 债表》（2013）一文中, 详细研究与分析了中央银行近13 年来的资产负债表, 得出中国的央行对金融机构的控制能 力不足, 饱存诸多问题, 且资产的涨幅要远高于发达国家, 货币发行占比较低的的现状, 也极大限制了央行对金融市 
场的调控能力。因此, 积极的在金融经济周期大背景下, 规划中国央行的负债表, 利用有效策略来改善负债表结构, 对中国经济有着重要的价值和意义。

\section{2. 中国的金融经济周期}

综合来看, 中国当前的经济状况为:经济增长缓慢, 用以刺激经济增长的相关政策尚未得到有效落实, 导致经 济开始出现滑坡现象并一度呈现低迷的状态。目前, 中国 的经济发展存在着许多问题，其中，金融资产的膨胀问题 比较典型, 而且这种现象在中国颁布新的经济政策后更加 显著[1]。除了这些直接影响中国经济发展的问题之外, 还 存在着不少的间接因素, 例如, 在资产供需双方的关系中,
股债关系的恶化致使经济版块不断收缩, 影响了金融企业 的发展, 导致该行业面临倒退停滞的局面。因而在制定新 的货币政策时, 需要进行全方位的考量, 实施更为严格有 效的金融调控手段。下图1为央行 2010 年以来负债表的规 模变动情况, 另外, 随着经济全球化的不断深入, 中国也 根据新的经济形势采取的新的经济政策, 创新了经济调控 手段, 例如为了调节利率, 鼓励扩大开支, 央行采取了量 化宽松的货币政策, 以增加基础货币供给, 降低市场利率, 进而对经济的增长起到一定的刺激作用。这些货币调控政 策均是以中央银行资产负债表以依托来调整, 因此, 从该 方面来说，金融资产负债表是进行货币政策调控的最关键 的参照项。

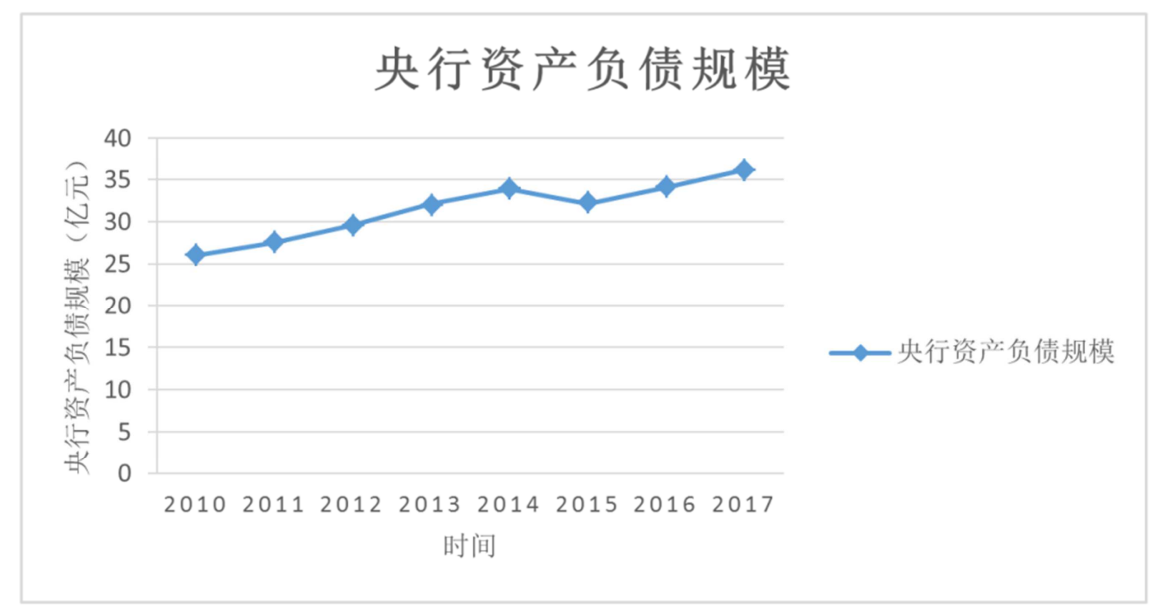

图1 央行资产负债规模。

如图1所示, 中国央行的资产负债规模整体呈现出稳 定式增长, 且据资料显示, 在2014年, 中国央行的总资产 与GDP之比 55.78 , 远高于美联储、欧行等的平均水平。 但是由于2014年金融危机爆发, 中国央行负债规模出现了 显著下跌, 也影响到了其资产总额与GDP的比值, 从绝对 比例角度研究, 中国央行的负债规模与国民生产总值的比 呈现出稳步下跌趋势。除此之外, 中国央行的负债表虽处 在迅速扩张阶段, 但是由于受到2008年经济危机影响, 其 扩张速度却在持续下降, 从 2007 年的 $130 \%$, 下跌至 2014 年的 $104.61 \%$, 仅用7年时间[2]。

\section{3. 中国的货币信用环境与金融经济周期的变化}

首先，2008年金额危机爆发以前，中国的经济在持续 增长, 货币信用也处于膨胀期。随着房地产价格的攀升, 信用贷款也在不断扩张, 金融市场开始出现的螺旋式的增 长。金融危机爆发后, 为了调控经济, 国家采取了一系列 的经济刺激措施, 然而在新的经济政策的调控下, 出现了 严重的金融膨胀, 资产泡沫等问题, 致使信用贷款以及货 币在存量上进一步扩大, 金融系统变得更加脆弱, 岩岩可 危。推动这些问题产生的背后原是由于家庭以及企业部门 的资产缩水严重, 各项经济活动持续萎缩, 资产负债表收 支不抵, 出现严重失衡。而在资金供需双方清理负债, 恢
复资产负债表的过程中, 让经济收缩的压力不断增长 [3]。 当压力达到一定程度时, 很有可能会造成经济衰退的局面。

其次, 在全球危机爆发的背景下, 中央银行也采取了 不同的应对措施, 转变了其运营模式, 例如, 在数量上放 宽限制, 在实际操作中做出转变。在这种运行模式的转变 中, 针对于中央银行的资产负债表策略实施相应的研究分 析, 就是促进政策制定合理性和科学性的前提和保证。以 外汇来源的资产为例, 这部分资产的增加, 有利于同步促 进央行资产负债表的扩张。

\section{4. 央行资产负债表策略}

\section{1. 货币总供给的数量}

首先, 对基础货币的供给调整是中央银行用以调控经济、 对付金融风险的重要举措之一, 也是实施资产负债表策略中 的关键一环。从调整范围上看, 包括各类储蓄存款、活期存 款以及现金等[4]。总的来说, 中央银行增加货币的总供给量 有两种方式。第一种方式为直接增加货币供应量, 这种方式 较为主动, 俗称“间接増印钞票”。或者通过回收基础货币, 实行再贷款这两方面来入手, 由于这一过程中不仅涉及到基 础货币的供给, 还与货币之间的乘数关系有很大的相关性。 由于货币间乘数关系比较复杂, 涉及到的因素比较多, 央行 应当对这种情况充分掌握并引起足够的重视。第二种方式为 
通过对政府的财政预算赤字进行控制，提升货币回收的流动 性, 从而实现对货币供给量的良好把控 [5]。

其次, 从货币供给这一单一概念的角度来说, 其涉及的 范围不仅包括了常规的基础货币, 还包括了货币乘数的关系。 且这个指标也是中央银行实行供给操作时需要关注的重点 问题。而从货币乘数这一指标的角度来看, 其又会受到多方 面因素的影响。例如外汇占款的影响、财政存款的影响、贷 款的影响等。只有在具体的供给操作中充分考虑以上几方面 的影响因素，才能最终使货币供给量指标得到优化。

\section{2. 资产负债表的传导机制}

资产负债表的传导机制对于中央银行在推进实行货 币政策的过程起着关键性的影响作用。这种传导机制对实 现资产负债表策略有重大的意义, 关乎到各项经济政策能 否得到有效落实。因此，全球金融专家们对资产负债表的 传导机制做了许多探讨研究, 希望能利用这种传导机制来 更好地实现对经济政策的有效落实。为了让资产负债表的 传导机制对资产负债表策略的价值最大化，应该从以下三 个方面入手进行控制和调整[6]。首先，为了使得金融资产 的结构性特征更加凸显，应着力调整不同资产间的替代关 系。其次，由于资产负债表对金融市场的摩擦度有一定的 影响, 因而在制定货币政策时应该尽量保证政策的科学性 以及合理性，从而降低其对金融市场的摩擦力度。最后, 由于私人企业的资产负债表对经济的宏观调控在一定范 围内也会产生作用, 因此国家应当重视这种作用, 鼓励健 全完善私企的资产负债表。

\section{5. 金融经济周期下中央银行资产负债表策略}

\section{1. 建立完备的准债务管理政策}

中央银行为了优化经济结构, 调整资产关系, 通过对 准债务管理政策中有关金融市场的相关政策规定进行适当 的调整来对政府债券市场进行调控。此种方式可以对私有 企业所持有政府债券的结构进行优化调整。有助于国民经 济的可持续发展，同时也能让经济的发展更好的适应社会 发展的需求。另外，管理政策的优化，可同步促进金融结 构的优化。这不仅仅包括上文所指的政府债券结构, 还包 括其他这种方式的金融发展形势的优化。而且，针对于资 产价格容易波动的情况, 相关的管理人员也可以通过完善 和调整债务管理的政策来对其起到宏观调控的作用。深入 推进准债务管理政策的完善能够让金融经济结构更加健康 良好, 能从根本上优化金融结构, 保持经济的稳健势头 [7]。

\section{2. 推动信用制度的不断完善}

虽然信用政策对性的对象主体是私人债务, 但是在调 整的过程中也会对金融市场产生一定的影响。一旦影响到 金融市场时, 中央银行可以通过对金融结构的所出现问题 的部分进行有针对性的调节。维持金融市场的稳定，让金 融市场发展与经济发展实现同步。通常, 中央银行推动信 用政策的主要途径是通过调整整体的经济结构来实现。而 且在调节的过程中, 中央银行也会根据具体的情况实施动
态的调整。央行推行的信用政策十分全面, 例如, 为了让 私人企业的贷款数额富余, 可以更改其债券的相关条目 [8]。

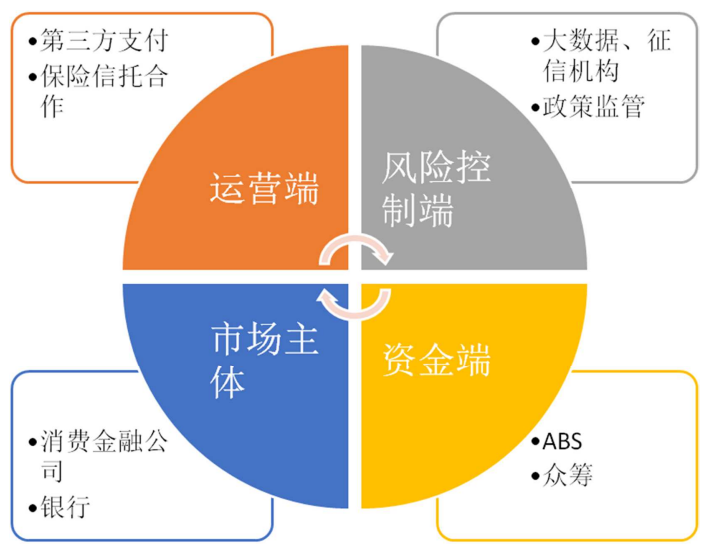

图2 信用体系简图。

如图2所示, 信用体系在信息化当下, 重要性日益提高, 无论是央行的风险控制、运营端还是资金端，都有良好的 信用管理制度, 因此, 完善信用政策对企业十分有利, 能 够有效的防控风险、整合资源，同时减少资金流失等问题。

\section{3. 健全汇率政策}

在汇率政策的调整上, 不断地健全和完善其制度内容, 以促进金融市场的发展为目标, 达到其发展过程中的具体 需求。在实际操作中, 为符合金融市场的需求, 契合金融 市场的发展, 需要对相关的汇率政策进行完善。其次, 健 全汇率政策主要针对的是外汇, 通过对私人企业的外汇净 出口进行适度的调整来优化汇率结构[9]。适当调节汇率大 小, 促进汇率实现良好波动, 从而促进金融市场的发展, 更好地满足经济发展的需要。最后, 在完善汇率政策的过 程中要综合考量金融经济周期的特征, 并根据这些特征来 具体调整相关汇率政策。政策的调整主要是从宏观调控的 角度来发挥作用, 最终制定出一个符合新时期经济常态及 发展周期的方案, 以便应对突发状况, 及时作出调整, 保 障经济稳定发展, 维护整个行业的秩序。

\section{4. 健全银行储备的相关政策}

中央银行在实施资产负债表策略的过程中, 可以通过 储备方面的政策对资产负债表起到一定的调节作用。对银 行储备政策进行调节主要是通过制定准备金政策来得以 实现。除此之外, 还可以将外部不断变化着的金融市场环 境作为参照来做出及时调整。及时对储备金目标进行确定 能够对私人企业的资产负债表起到一定程度上的约束作 用。2008年国际金融危机结束后，各国的中央银行对于利 用资产负债表这一手段开始重视起来。例如, 美国联邦储 蓄银行开始加大国债的持有量, 并且提高机构债券以及其 他债券的发行数量。欧洲中央银行也开始着手购买有私企 发行的担保债券, 并且增加对于欧元区国家的债券购买量。 这些中央银行采取此类措施手段的主要目的就是为了提 高长期融资的数量, 同时扩大抵押品和担保, 以便使得再 融资的期限增加, 让同业市场不再顶受那么大的压力。除 
了上述银行所采取的措施之外, 一些中央银行为了让货币 的融资环境得到一些改善, 还未主权债券的借贷创造十分 有利的条件。例如, 美国联邦储蓄银行就在房地产商处购 买了一定的抵押以及不定产债券（该房地产商是由政府提供 资助)。事实上, 中央银行要想调整基准利率可以通过购买公 共债券来实现。但需要注意两点, 中央银行采取操作时, 自身 将会受到资产负债表政策多大程度上的影响取决于其融资方式。 倘若某一债券的减少导致了另一债券的增加, 在这种情况下, 总体的债券规模不会受到太大的影响。

\section{5. 建立合理有效的资产调整体系}

首先, 为了保证各种经济调控政策在具体的实施过程 中不发生内部的冲突, 让经济市场出现较大的波动, 中央 银行必须对各方面因素进行考量, 综合考虑到金融资产价 格是否会一对金融市场产生不利的影响，资产价格的下降 或上升是否会影响到某项货币政策的实际效用，因而中央 银行需要密切关注资产价格的升降并且防控风险, 建立一 套合理有效的资产调整体系; 其次, 当资产价格的波动情 况表现正常, 而且信用贷款与总需求没有出现缩进的情况, 中央银行此时无须对其作出相应的调整举措。这种情况说 明央行所实施的货币政策并没有造成不间断的货币紧缩, 央行所采用的调节措施对货币所产生的破坏作用是十分
不稳定的 [10]。因此为了防控潜在的金融风险, 中央银行 应该综合考虑，洞悉金融经济周期的特征，建立起一套合 理有效的资产调整体系[11]。

\section{6. 权衡金融、货币以及经济三者之间的稳定关系}

从金融经济系统本身的特点上来分析, 其整体系统的 稳定性较弱, 当其经济周期经由最顶峰的时段进一步推进 后，其发展趋势将进入缓慢衰退期。当金融经济进入到周 期的下行阶段时, 此时的经济稳定性较差, 比较脆弱的特 点便会体现出来, 这种状况会使得经济发展受到限制, 而 同时, 由于经济增长的放缓会加大金融资产负债表的压力, 导致资产负债表恶化, 甚至会对整个国民经济的发展构成 严重的阻碍, 导致经济停滞乃至下滑的风险日益严峻 [12]。 事实上，金融稳定、货币稳定以及经济稳定三者之间存在 着密不可分的关系, 三者之间需要达到一种相对平衡的状 态才能让经济保持一种健康良好的状态。经济增长的过程 中, 各种风险始终存在, 并且伴随着经济周期在不断地变 化着, 因此, 中央银行应该时刻关注资产的变动, 综合分 析债务双方的关系, 构建多目标的函数对金融经济做有效 的把控与调整[13]。

\begin{tabular}{|l|l|l|l|l|l|}
\hline 报表项目 & 2010 年 & 2011 年 & 2012 年 & 2013 年 & 2014 年 \\
\hline 国外资产 & 215419.6 & 237898.06 & 241416.90 & 272233.53 & 278622.85 \\
\hline 外汇 & 206766.7 & 232388.73 & 236669.93 & 264270.04 & 270681.33 \\
\hline 货市黄金 & 669.8 & 669.84 & 669.84 & 669.84 & 669.84 \\
\hline 其他外国资产 & 7983.1 & 4839.49 & 4077.13 & 7293.66 & 7271.68 \\
\hline 对政府债券 & 15421.11 & 15399.73 & 15313.69 & 15312.73 & 15312.73 \\
\hline $\begin{array}{l}\text { 对其他存款性公司 } \\
\text { 债券 }\end{array}$ & 9485.70 & 10237.54 & 16701.08 & 113147.90 & 2498527 \\
\hline $\begin{array}{l}\text { 对其他金融性公司 } \\
\text { 债券 }\end{array}$ & 11325.81 & 10643.97 & 10038.62 & 8907.36 & 7848.81 \\
\hline 对非金融公司债券 & 24.99 & 24.99 & 24.99 & 24.99 & 11.62 \\
\hline 其他资产 & 7597.67 & 6763.31 & 11041.91 & 7652.04 & 11467.50 \\
\hline 总资产 & $\mathbf{2 5 9 2 7 4 . 8 9}$ & $\mathbf{2 8 0 9 7 7 . 6 0}$ & $\mathbf{2 9 4 5 3 7 . 1 9}$ & $\mathbf{3 1 7 2 7 8 . 5 5}$ & $\mathbf{3 3 8 2 4 8 . 7 9}$ \\
\hline 诸备货市 & 185311.08 & 224641.76 & 252345.17 & 271023.09 & 294093.02 \\
\hline 货市发行 & 48646.02 & 55850.07 & 60645.97 & 64980.93 & 67151.28 \\
\hline $\begin{array}{l}\text { 其他存款性公司存 } \\
\text { 款 }\end{array}$ & 136480.86 & 168791.68 & 191699.201 & 206042.17 & 226941.74 \\
\hline $\begin{array}{l}\text { 不计入诸备货市的 } \\
\text { 金融性公司存款 }\end{array}$ & 657.19 & 908.37 & 1348.85 & 1330.27 & 1558.35 \\
\hline 传券发行 & 40497.23 & 23336.66 & 13880.00 & 7762.00 & 6522.00 \\
\hline 国外员债 & 720.23 & 2699.44 & 1464.24 & 2088.27 & 1833.83 \\
\hline 政府存款 & 24277.32 & 22733.66 & 20753.27 & 28610.60 & 31275.33 \\
\hline 自有资金 & 219.75 & 219.75 & 219.75 & 219.75 & 219.75 \\
\hline 其他负债 & 7592.23 & 6437.97 & 4525.91 & 6244.57 & 2746.51 \\
\hline 总负债 & $\mathbf{2 5 9 2 7 4 . 8 9}$ & $\mathbf{2 8 0 9 7 7 . 6 0}$ & $\mathbf{2 9 4 5 3 7 . 1 9}$ & $\mathbf{3 1 7 2 7 8 . 5 5}$ & $\mathbf{3 3 8 2 4 8 . 7 9}$ \\
\hline
\end{tabular}

图3 近五年中国人民银行资产负债表。 
从上图 3 可知, 中国央行的总负债中, 中外汇数量占 比要远超其他, 因此, 应逐渐降低其比例, 企业必须要实 现从“引进来”到“走出去”的过度, 来缓解外汇流入的压力, 而货币政策的有效性将直接决定外汇输出的路径能否拓 宽, 可见保证国际经济以及货币政策之间的稳定关系, 对 于改善中国央行的负债表结构有着重要的意义及价值。

\section{7. 将金融、货币以及经济三者稳定纳入统一的框架内}

2008年金融危机爆发以来, 中央银行在疏通货币政策 方面主要采取的措施是通过实行定向操作。为了引导资金 通过一些例如信用贷款之类的途径流向实体经济。世界各 大银行组织均采取了相应的政策。例如, 美联储为了打断 短期利率, 实现长期利率, 采用了“扭转操作”[14]。与此 同时, 欧盟中央银行也采取了类似的定向措施。在各个银 行采取这些措施的过程中, 值得注意的是, 银行对于货币 的结构调整与银行的调整手段和使用的调节工具是息息 相关的。资产负债表就可以作为一项十分有效的结构性调 节工具。资产和负债虽然有一定的相似之处, 但是二者不 能互相替代。中央银行对其资产负债表做出一定的调整会 改变资产的供给, 因此也就会使得银行的收益率也发生相 应的改变。银行通过此种措施来可以对收益率进行调整进 而可以影响到私企的选择。因而, 改变资产与负债二者之 间的相互替代关系是银行资产负债表策略的根本核心, 如 此一来, 从总量上来看, 货币也就具有了一定的结构性特 点。当经济处于周期中的下行阶段, 资金的流动性风险增 加, 银行盈利处于低迷状态, 在这种情况下, 企业部门以 及公众会降低存款的意愿, 认为持有现金在手反倒比较稳 定安全。此时, 在降低基准利率很难达到刺激边际效益的 效果。虽然要保持货币政策的稳健符合当前国家支持实体 经济这一主要方向趋势, 但前提是在此过程中必须要把金 融、货币以及经济三者之间的关系纳入统一的框架结构中 [15]。为达到这一目标, 对于货币政策的实行要坚持多元 化的原则, 应创新货币的操作工具, 让操作工具更加多样 化, 如此才能真正实现金融、货币以及经济三者的稳定, 实现三者的平衡发展。

\section{6. 结论}

总之, 要提出有效的中央银行资产负债表策略, 首先 就应当明确金融经济周期的内涵及中国金融经济周期变 化的特点, 只有将这两部分概念理解充分, 并在一定时期 和范围内把握好中国金融经济周期变化的特点, 才能提出 有效的资产负债表策略, 且在策略提出时, 要注意其全面 性，应从货币供给、制度与政策的建立健全以及整个资产
调整体系的建立入手, 确保资产负载表策略在金融经济周 期的变化中良好的适应。

\section{参考文献}

[1] 孙双鹰. 金融经济周期理论研究动态 [J]. 中国经 贸,2017(17).1-1。

[2] 何德旭,张捷.构建金融经济周期下的中国利率走廊模式 [J]. 新金融,2017(12):4-10。

[3] 颜博.中央银行资产负债表分析[J].现代商业,2013(8):41-42。

[4] 许珊珊.经济“新常态”下中国货币政策框架转型研究——探 索“利率走廊”调控模式[D].安徽财经大学, 2016 。

[5] 益言.主要经济体中央银行资产负债表政策简析[J].中国货 币市场,2016(9):60-66。

[6] 崔丰慧. 经济波动、货币政策与企业融投资行为研究[D].东 北财经大学,2017。

[7] 赵继鸿.金融危机视角下的货币政策决策研究 [D].湖南大 学,2013。

[8] 中国人民银行南昌中心支行会计财务处课题组. 浅议发达 经济体中央银行资产负债表政策溢出效应——基于央行资 产负债表分析 [J].金融与经济,2015(10):63-66。

[9] 何德旭,张捷.金融经济周期中“货币”与“信用”紧平衡的探 讨 [J].上海金融,2017(09):3-7。

[10] 郭红玉,张运龙.基于资产组合再平衡渠道的央行资产负债 表政策溢出效应研究[J].世界经济研究,2016(6):32-42。

[11] 陈静.量化宽松货币政策的传导机制与政策效果研究— 基于央行资产负债表的跨国分析 [J]. 国际金融研 究,2013(2):16-25。

[12] 于海滨.主要经济体中央银行资产负债表研究——结构 管理的视角[J].金融与经济,2016(5):58-60。

[13] 程海明,周学园.新兴经济体中央银行资产负债表管理研究 ——基于会计学和经济学视角[J].金融纵横,2016(9):67-75。

[14] 中国人民银行南昌中心支行会计财务处课题组. 浅议发达 经济体中央银行资产负债表政策溢出效应——基于央行资 产负债表分析[J].金融与经济,2015(10):63-66。

[15] 王洋天.中央银行资产负债表与量化宽松货币政策研究 ——基于美联储资产负债表的考察 [J]. 投资研 究,2013(11):150-160。 